\title{
Assessment of flexural analysis applied to the Sumatra-Java subduction zone
}

\author{
R T Ratheesh KumaR ${ }^{\dagger}$, Tanmay K Maji and Rajesh R NaiR* \\ Department of Geology and Geophysics, Indian Institute of Technology, Kharagpur 721 302, India. \\ ${ }^{\dagger}$ Presently at Department of Ocean Engineering, IIT, Madras. \\ * Department of Ocean Engineering, Indian Institute of Technology, Madras, Chennai 600 036, India.
}

\begin{abstract}
Indian Ocean subduction zone is one of the most active plate margins of the globe as evident from its vast record of great magnitude earthquake and tsunami events. We use Bouguer admittance (Morlet isostatic response function) in Sumatra-Java subduction zones comprising both the subduction and over-riding plates to determine the lithospheric mechanical strength variations. We determine effective elastic thickness $\left(T_{e}\right)$ for five oceanic windows (size $990 \times 990 \mathrm{~km}^{2}$ ) by analyzing the admittance using Bouguer gravity and bathymetry data. The results show bimodal $T_{e}$ values $<20 \mathrm{~km}$ for Sumatra and $20-40 \mathrm{~km}$ for Java. The lower bimodal values obtained for Sumatra appears to correlate well with the zones of historical seismicity. This is in sharp contrast with Java subduction zone, which shows higher $T_{e}$ values $(20-40 \mathrm{~km})$ and apparently associated with low magnitude earthquakes. We suggest a strong and wide interseismic coupling for Sumatra between the subducting and over-riding plates, and deeper mantle contributing to low strength, shallow focus - high magnitude seismicity and vice versa for Java, leading to their seismogenic zonation.
\end{abstract}

\section{Introduction}

The mechanical strength of the lithosphere can be described by its stability under deforming forces (Burov and Diament 1995; Watts and Burov 2003; Audet and Mareschal 2004). The effective elastic thickness $\left(T_{e}\right)$ parameterizes a numerical expression for the strength of the plate (Watts 2001). Continental lithospheres exhibit a high range of $T_{e}$ generally with a bimodal distribution of an average minimum range of $20 \mathrm{~km}$ and an average maximum of $80 \mathrm{~km}$. They depend primarily on factors such as composition, geometry, thermal structure and state of stress of the lithosphere due to external forces (Burov and Diament 1995). $T_{e}$ variation of the oceanic plate is generally attributed to its thermal age, and hence $T_{e}$ increases with the age of the oceanic lithosphere.

Subduction zones are unique among all the active plate margins for their college of deviatoric tectonic forces and dynamics. Recent studies indicate that within the subduction zone, the fore-arc segment is a potential site for frequent earthquakes of large magnitudes due to the frictional forces at the interface between the subducting and over-riding crustal segments (Seno 2005; Grevemeyer and Tiwari 2006; Konca et al 2008; Chileh et al 2008). This frictional interface is known as the interseismic coupling zone, which is assumed to be an important factor in determining the magnitude of shallow earthquakes. Extensive studies on Negative Trench Parallel Gravity Anomaly (NTPGA) and regions with strong positive gravity anomaly (Song and Simons 2003) demonstrate seismic and aseismic nature respectively. Their conclusions are consistent with a model in which frictional properties of subducting and over-riding plate influences gravity and seismogenic behaviour. Grevemeyer and Tiwari (2006) demonstrated the effective NTPGA by modeling Sumatra with a wider interseismic coupling zone and a deeper fore-arc mantle,

Keywords. Fore-arc; trench axis; interseismic coupling; isostasy; Bouguer admittance; effective elastic thickness $\left(T_{e}\right)$. 
and Java with a narrow interseismic coupling zone and a shallow fore-arc mantle. They further infer that the seismicity is indeed controlled by interseismic coupling and fore-arc configuration. Llenos and McGuire (2007) compared synthetic and observed seismograms of the first orbit Rayleigh wave for a fore-arc structure, inverted the amplitude and arrival time measurements and hence estimated the slip distribution. Their studies reveal that increase in TPGA is dependent on the physical conditions along the plate interface that favours rupture termination. The interseismic coupling can be correlated to a number of factors such as the age-heat flow parameters of the subducting crust, major bathymetric structures (e.g., ridge segments) present on the subducting lithosphere, convergence rate, direction of plate convergence (oblique or normal), position of fore-arc mantle (deep lying or shallow lying) and the amount of serpentinization at the fore-arc mantle (Seno 2005; Grevemeyer and Tiwari 2006; Llenos and McGuire 2007).

Our approach is much similar to the recent published results of flexural analysis along the Andean margin (Perez-Gussinye et al 2008) and its relationship to subduction geometry. They used 2D multitaper coherence of Bouguer gravity and topography data and obtained $T_{e}$ variations that are highest $(\sim 40 \mathrm{~km})$ in the forearc $\left(\sim 20^{\circ} \mathrm{S}\right)$ in the Andean margin and interpreted this $T_{e}$ structure due to conductive cooling of the continent by the subducting slab. In addition, a low $T_{e}$ of $20 \mathrm{~km}$ in the central Andes along the volcanic chain and Altiplano plateaus is interpreted as being due to high geothermal gradient. Perez-Gussinye et al (2008) used large window sizes $600 \times 600 \mathrm{~km}^{2}$ and their further analyses and tests revealed that the window size could retrieve $T_{e}$ values up to $60 \mathrm{~km}$. These results are consistent with the $T_{e}$ ranges obtained by 2D forward modeling of Andres (2005). In another study Tassara et al (2007) using a land-ocean scheme in South American plate were advised to use the Banks model (Banks et al 2001) instead of the Forsyth model to avoid numerical instabilities if the anomalies have shallow sources in a subduction scenario. Their analysis could reveal a rigidity structure which follows segmentation of the seismogenic zone along the subduction fault. We thus used the more appropriate Banks model (Banks et al 1977) in our present analysis using Bouguer Admittance method along the Indian Ocean subduction zone and adjoining Ninetyeast Ridge (NER) to test whether rigidity structure in the study area had a causal relationship with segmentation of the seismogenic zone. We agree that the formalism assumes that we have only vertical 'loads', no horizontal stresses, and that the mantle is effectively 'fluid'. In contrast, a subduction zone will be pushed from the side, have a hanging edge, and transmit stresses inside the slab. We would emphasize here that our present study is a first order estimate of 'effective' elastic thickness, and that the word 'effective' is to be understood as that which is the best match under these conditions. We will thus verify the seismogenic segmentation of the Burma-Sunda fore-arc with an improved recovery of spatial variations in $T_{e}$ using Bouguer admittance based fan wavelet methodology (Kirby and Swain 2006). Our analysis will focus on a correlation between the spatial variations of $T_{e}$ and the occurrence of large magnitude earthquakes in the fore-arc zone.

\subsection{Geodynamic setting}

A classical example of a subduction system in the north eastern Indian Ocean includes the Andaman-Sumatra and Java regions. The subduction is resumed to commence from early Cretaceous (Scotese et al 1988) extending from Eastern Himalayan syntaxes to Sunda arc. The subduction system is composed of the down going IndoAustralian slab beneath the Sunda and Burma tectonic plates (Curray et al 1979; Kamesh Raju et al 2007; Curray 2005). The subduction of oceanic crust of different ages and with different rates (Krishna et al 1995, 1999; Gopala Rao et al 1997; Kamesh Raju et al 2007) resulted in a varying slab geometry in the Sumatra-Java regions. The major features formed due to this process are an accretionary wedge, the outer arc forming the backstop and fore-arc basins (Samuel et al 1997; Schliuter et al 2002). Figure 1 shows the subduction zone segments comprising Burma plate (Andaman, Nicobar Islands and offshore of Northern Sumatra), and Sunda plate (southern Sumatra and Java).

The other prominent structures on the subducting plates adjacent to the subduction zone are the aseismic ridge segments such as Ninetyeast Ridge (NER), Investigator Ridge, etc. The NER is one of the longest linear features on earth, extending from $31^{\circ} \mathrm{S}$ to $17^{\circ} \mathrm{N}$ following the $90^{\circ} \mathrm{E}$ meridian, trending NNE-SSW, and is lying in close proximity to the Andaman-Sumatra subduction zone. Gravity estimations over NER show a slightly positive free-air anomaly, concluding that the ridge topographic load is compensated by a deep root of Moho deflection into the mantle (Krishna et al 2001). The studies indicate that the ridge subduction complexities have not yet initiated for the NER, but may be advancing towards an initial stage of convergence processes (Subrahmaniam et al 2008). The direction and rate of subduction of the Indo-Australian plate along the trench is quite different from Sumatra to Java (Grevemeyer and Tiwari 2006; Lasitha et al 2006; 


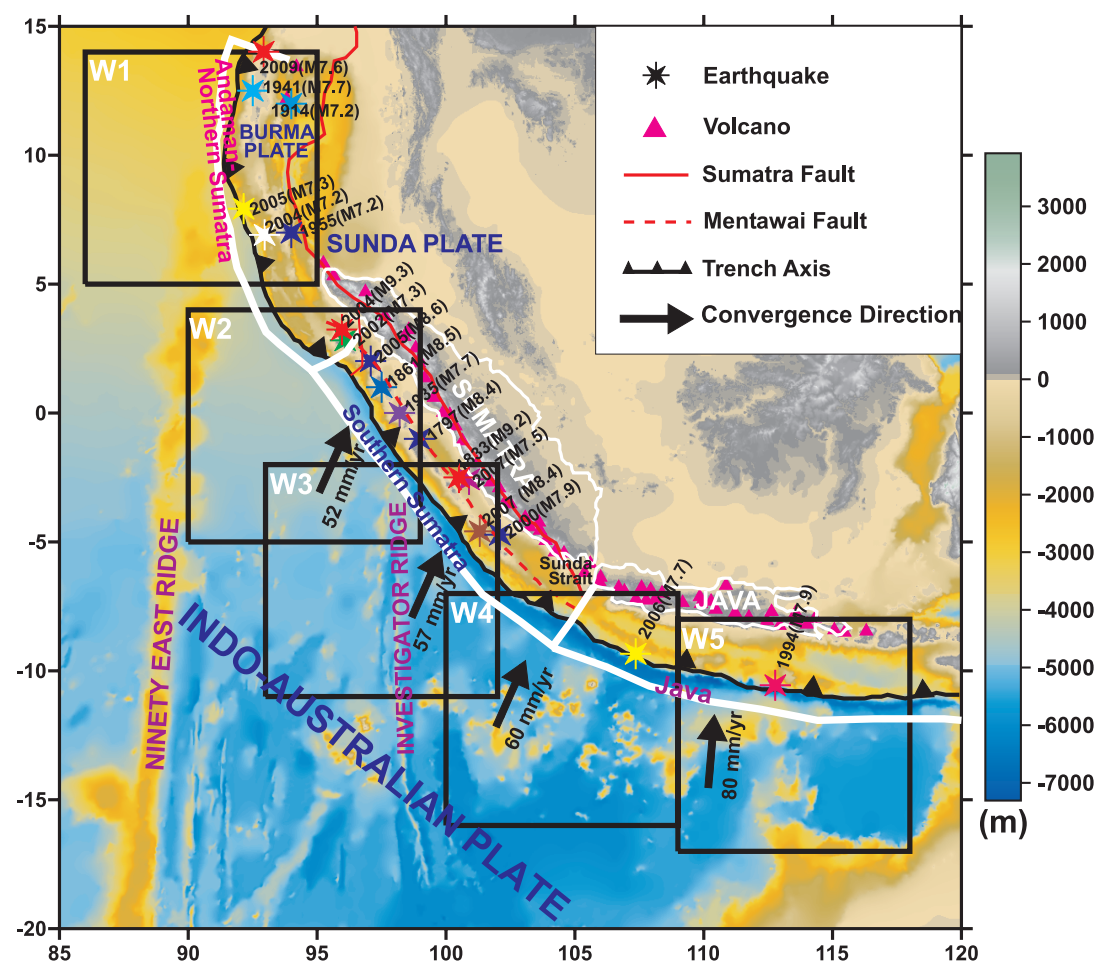

(a)

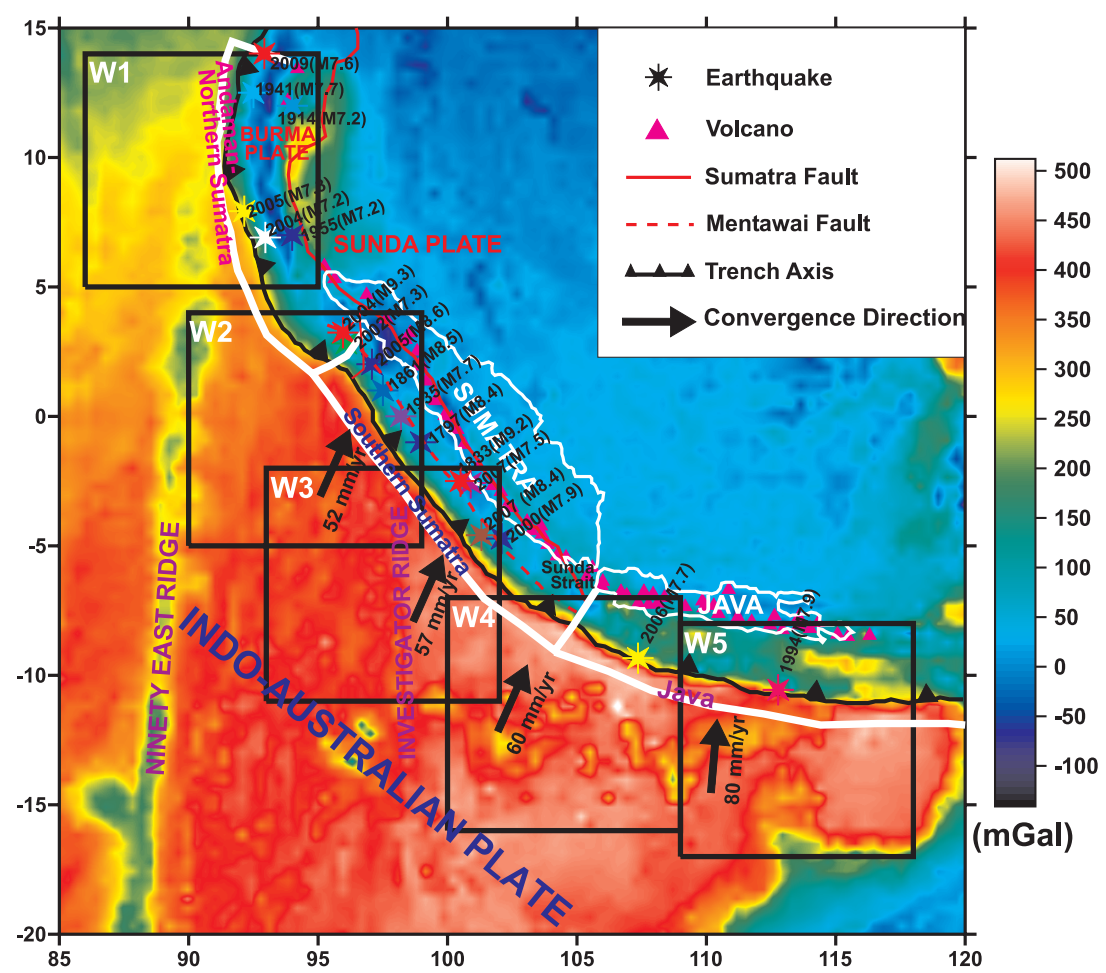

(b)

Figure 1. (a) Tectonic setting of the Andaman-Sumatra-Java subduction zone, superimposed on GEBCO bathymetry and (b) Bouguer gravity map, exhibiting the major morphological features on the Indo-Australian (subducting) plate and the Sunda-Burma (over-riding) plate; such as Ninety-East Ridge (NER), Investigator Fracture Zone, trench axis, Sumatra Fault, Mentawai Fault, Sumatra-Java islands, etc. The region between the trench axis and the island chain is the fore-arc segment on which epicenters of several recent and historic megathrust earthquake events $(M>7 ; 1797-2007)$ have been plotted (stars). The thick white line is demarcating the subduction zone segments which include Andaman-Northern Sumatra, Southern Sumatra, and Java, based on their seismicity and morphotectonic trends. The thin white line is demarcating the coastal boundaries of Sumatra and Java islands. Windows (W1, W2, W3, W4 and W5) are representing the selected areas for the $T_{e}$ estimation. 
Irsyam et al 2008). Normal subduction of an old lithosphere $(\sim 130 \mathrm{Myr})$ at a fast convergence rate $(\sim 80 \mathrm{~mm} / \mathrm{yr})$ is the characteristic of Java subduction zone. On the other hand, in Sumatra, a comparatively young lithosphere $(\sim 53 \mathrm{Myr})$ (Krishna et al 1995; Simoes et al 2004) is subducting in an oblique manner at a slow convergence rate $(\sim 52$ $60 \mathrm{~mm} / \mathrm{yr}$ ) (Lasitha et al 2006). Oblique subduction leads to the procreation of the two strike slip fault components in the Sumatra margin, known as Sumatra and Mentawai fault segments (Malod 1995). The nature of seismicity also differs from Sumatra to Java. Sumatra fore-arc is characterized by a vast record of great historic earthquakes like that of 1797 (M8.4), 1861 (M8.5), 2004 (M9.3), 2005 (M8.6), 2007 (M8.4), etc. (Grevemeyer and Tiwari 2006; Chlieh et al 2008; Konka et al 2008; http://earthquake.usgs.gov/regional/neic). While Java fore-arc is so far less seismically disturbed. Great earthquakes $(M>8)$ and active, deep lying fault segments are rare in this region. Geodetic measurements over the Sumatra fore-arc zone reveal a heterogeneous pattern of coupling along the plate interface. The patchwork of high coupling (interseismic strain accumulation) correlates well with the rupture areas of large magnitude earthquakes (Chlieh et al 2008; Konca et al 2008).

\section{Data analysis}

Recently, Kirby and Swain (2007) demonstrated that $T_{e}$ was better recovered in all settings (i.e., land only, sea only and mixed land sea) when using the scaling (equivalent topography) and landloading equations. Hence we converted bathymetry to equivalent topography and free-air anomalies to complete Bouguer anomalies whose details are given here. We have used the free-air gravity data derived from the Global marine gravity field from ERS-1 and GEOSAT geodetic mission altimetry of Anderson and Knudsen (1998) and Anderson et al (2008). The free-air gravity anomaly data, $\Delta G_{f}$ is converted to Bouguer gravity anomaly, $\Delta G_{b}$ using the slab formula and a surface rock water density contrast of $\Delta \rho=1670 \mathrm{kgm}^{-3}$, applied to the bathymetry data:

$$
\Delta G_{b}=\Delta G_{f}+2 \pi \Delta \rho G H
$$

where $H$ is the bathymetry in meters. We used the formula of Parker (1972) and then estimated the complete Bouguer anomaly which is used for the present estimation. The bathymetry data come from GEBCO Digital 1 minute bathymetry data (NOAA 2003), which is converted to equivalent topography.
The equivalent topography is the height or depth the crust will assume in the absence of ice or water present and under isostatic conditions (Daly et al 2004) which is given by:

$$
h(x)=\left(\frac{\rho_{c}-\rho_{w}}{\rho_{c}}\right) * d,
$$

where $h(x)$ is the equivalent topography, $d$ is the bathymetry (in meters), $\rho_{c}$ and $\rho_{w}$ are the mean crustal density $\left(2800 \mathrm{~kg} \mathrm{~m}^{-3}\right)$ and the water density $\left(1030 \mathrm{~kg} \mathrm{~m}^{-3}\right)$ respectively. Bouguer and free-air admittance are both functions only of the topography and the gravity field, and only the manner of data reduction differs between both methods. When properly accounted for in the analysis, the Bouguer correction should not influence the statistics of the result; this matter seems to be a question of recent interest (Kirby and Swain 2007). Ultimately, the discriminant should be whether the theoretical admittance curves are well fitted by the model, and we have found this to be the case. Recently, Luis and Neves (2006) used Bouguer admittance methodology in Azores plateau which is a large bathymetric anomaly in the central north Atlantic confirming the flexural isostatic mode with Moho depth of $12 \mathrm{~km}$ and $T_{e}$ in the range of 3-6 km. In another work Billen et al (2003) used the admittance function between scaled bathymetry and geoidal anomalies as a constraint in viscosity and buoyancy in a 3-D regional dynamic model. The crustal thickness data used is from the CRUST 2 model (Bassin et al 2000). The other restrictive conditions in the implementation of Bouguer admittance is overcome by analyzing the study area in window sizes $\left(990 \times 990 \mathrm{~km}^{2}\right)$ which is several times the flexural wavelength of the lithosphere and the data samples the same tectonic province and thus ensures that integrated strength is corresponding to the tectonic province. Figure $1(\mathrm{a}$ and $\mathrm{b})$ shows the tectonic setting plotted on the bathymetry and the Bouguer anomaly map, respectively.

\section{Methodology}

The fan wavelet (Kirby and Swain 2004) is the superposition of 2D Morlet wavelets arranged in 'fan' shaped geometry. The coherence or admittance is obtained by estimating the cospectra and cross spectra of the gravity and topography data. Instead of Fourier transform, continuous wavelet transform (CWT) is employed to compute the local power spectra.

The CWT of a 2D spatially distributed signal $g(x)$ is estimated by taking the convolution of 
the signal with the complex conjugate of a wavelet:

$$
\tilde{g}(s, \mathbf{x}, \theta)=\mathbf{F}^{-1}\left\{\hat{g}(\mathbf{k}) \hat{\psi}_{s, \theta}^{*}(k)\right\}
$$

where $\tilde{g}(s, \mathbf{x}, \theta)$ is the complex wavelet coefficient, $s$ is the width or dilation responsible for the resolution of the wavelet, $\theta$ is the rotation parameter, $k$ is the $2 \mathrm{D}$ wave number, $\mathbf{F}^{-1}$ is the inverse $2 \mathrm{D}$ Fourier transform, $\hat{g}(\mathbf{k})$ is the $2 \mathrm{D}$ Fourier transform of the signal $g(\mathbf{x}), \hat{\psi}_{s, \theta}^{*}(\mathbf{k})$ is the complex conjugate of $\hat{\psi}_{s, \theta}(\mathbf{k})$, where

$$
\hat{\psi}_{s, \theta}(\mathbf{k})=s \hat{\psi}\left(s \Omega^{-1}(\theta) \mathbf{k}\right)
$$

is the 2D Fourier transform of the 'daughter' wavelets which are obtained by dilating, translating and rotating the mother wavelet. $\Omega(\theta)$ is the rotation matrix. Superposition of Morlet wavelets is performed to produce isotropic and complex wavelet coefficients. The admittance is obtained by taking the ratio of cross spectra of gravity and topography to power spectra of gravity:

$$
Z(s, x)=\frac{\left\langle\tilde{g}_{s x \theta} \tilde{h}_{s x \theta}^{*}\right\rangle_{\theta}}{\left\langle\tilde{g}_{s x \theta} \tilde{g}_{s x \theta}^{*}\right\rangle_{\theta}},
$$

where $\tilde{g}_{s x \theta}$ and $\tilde{h}_{s x \theta}$ are the complex wavelet coefficients of Bouguer anomaly and topography/ bathymetry, respectively.

The advantage of fan wavelet method over other spectral methods in isostatic calculations lies in the fact that the CWT provides local as well as global spectra unlike the FT which yields only global spectra. Although the windowed Fourier transforms (e.g., multitaper method) provides spatial variations, the fan wavelet is still better since it employs an optimal-sized window for each scale (Kirby and Swain 2004).

\section{Spatial $T_{e}$ analysis and results over Sumatra-Java subduction zones}

Five windows (W1, W2, W3, W4 and W5) of size $990 \times 990 \mathrm{~km}^{2}$ are used to compute the effective elastic thickness $\left(T_{e}\right)$ of the Sumatra-Java subduction zone. The spatial resolution of the $T_{e}$ output is $0.1^{\circ}$ which reveals the regional spatial variations. Figure 2 (W1) represents the Andaman-Northern Sumatra subduction zone. A predominantly high range of $T_{e}(40-65 \mathrm{~km})$ is observed over the forearc segment, which is the epicenter location of a number of historic and neotectonic earthquakes including the events of 1914 (M7.2), 1941 (M7.7), 1955 (M7.2), 2004 (M7.2), 2005 (M7.3), 2009 (M7.6) and others. A small portion of forearc through which the Sumatra Fault is running, exhibits a reduction of lithospheric strength $\left(T_{e}<40 \mathrm{~km}\right)$. The NER in the Indo-Australian plate which is lying in close proximity to the trench axis, shows a low $T_{e}$ range $(0-25 \mathrm{~km})$.

Figure 2 (W2) includes part of the northern and southern Sumatra subduction zone. Eastern portion of the NER included in figure 2 (W2) exhibits a low $T_{e}$ range $(\sim 0-15 \mathrm{~km})$. The region between the NER and the trench axis demonstrates an overall moderately high $T_{e}$ range. Isostatic response analysis over the fore-arc segment reveals an anomalously low Fore-arc $T_{e}\left(L F T_{e}\right)$ range $(0-20 \mathrm{~km})$ which coincides with the epicenter locations of 2004 (M9.3), 2002 (M7.3), 2005 (M8.6), 1861 (M8.5), 1935 (M7.7), and 1797 (M8.4) major earthquake events. The Mentawai strike-slip fault runs across the $L F T_{e}$ zone, appears to align with all of these earthquakes showed in W2. The southern Sumatra subduction zone, W3 (figure 2) captures a low $T_{e}(<15 \mathrm{~km})$ over the Investigator Ridge segment which lies on the subducting oceanic plate near to the trench axis. A significant wide $L F T_{e}$ patch $\left(T_{e}<20 \mathrm{~km}\right)$, again aligned with the historic and neotectonic megathrust events (Grevemeyer and Tiwari 2006; Konca et al 2008) (1833, M9.2; and the events happened in 2007: M8.4 and M7.9) which occurred adjacently on both sides of the Mentawai fault, is the characteristic feature of southern Sumatra fore-arc. A comparatively high range of $T_{e}(20-40 \mathrm{~km})$ is captured in the W4 (figure 2), comprising the Java fore-arc region. A neotectonic major earthquake of 2006 (M7.7) has occurred in the low $T_{e}$ zone so far in this region. The randomly distributed bathymetric masses contribute a low $T_{e}$ over the subducting oceanic plate. Finally, figure 2 (W5), which is the continuation of Java subduction zone shows a comparatively high range of $T_{e}(20-40 \mathrm{~km})$ throughout the forearc zone. One major earthquake event of 1994 (M7.9) occurred in this high $T_{e}$ fore-arc zone. The prominent $T_{e}$ low over the oceanic plate can be observed over the intermittently scattered bathymetric highs. The error in $T_{e}$ estimation (figure 3 ) $\delta Z(\mathbf{k})$ is found to be varying from $0-4 \mathrm{~km}$ for all the windows, which indicates qualitatively that the admittance estimate is robust. In the current study using the fan wavelet technique the error in estimating $T_{e}$ has been performed by considering the reciprocal wavenumber weighting between the observed and predicted admittance. The errors obtained by this technique are proportional to the equivalent Fourier wavenumber. Contrary to other error estimation methods, this method underestimates the noisy admittance estimates occurring at 

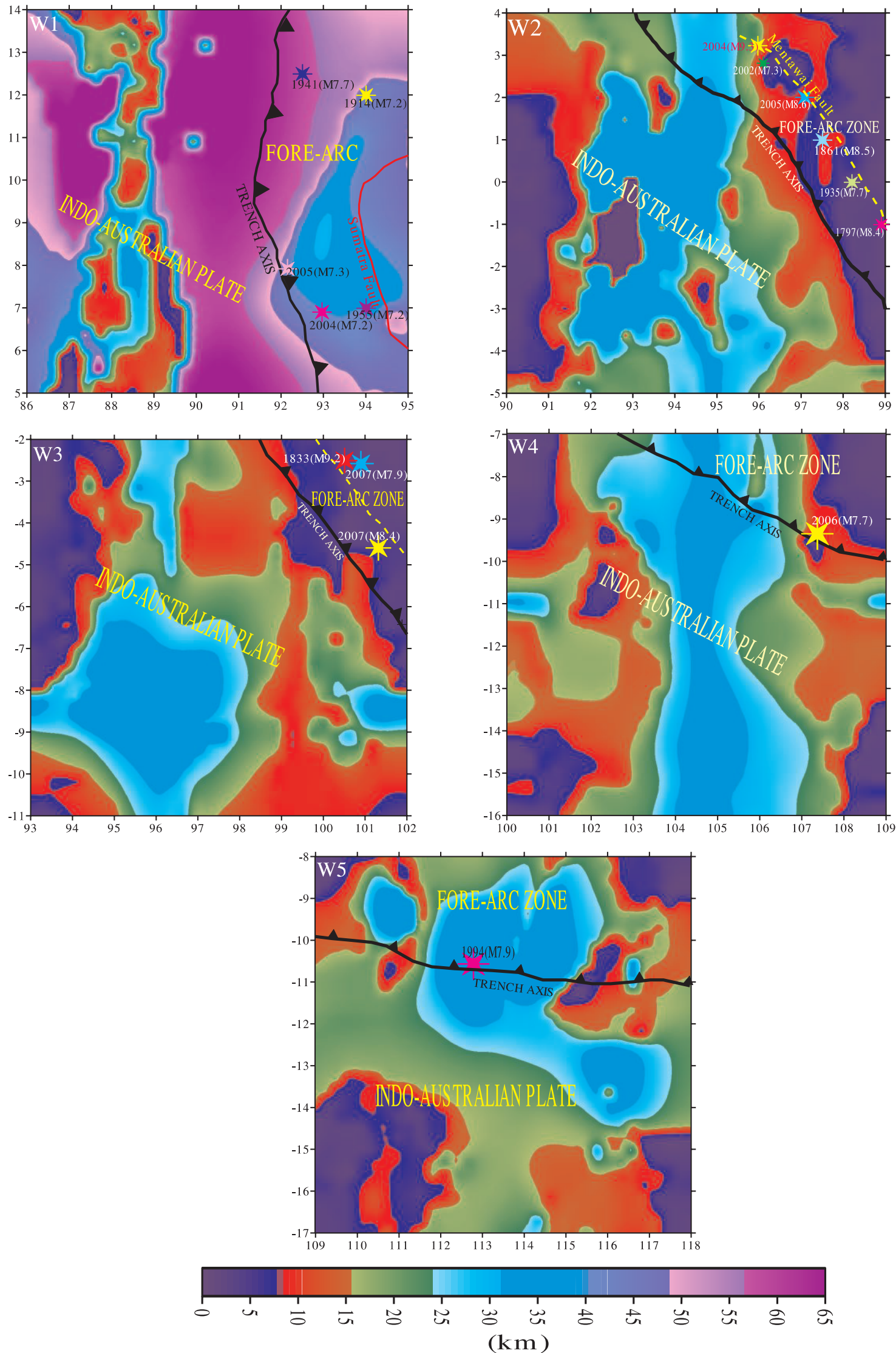

Figure 2. Estimated effective elastic thickness $\left(T_{e}\right)$ maps for the corresponding windows (W1, W2, W3, W4 and W5) showed in figure 1 . Each $T_{e}$ window is marked by the epicenter locations (stars) of major earthquake events $(M>7)$ in that region. 

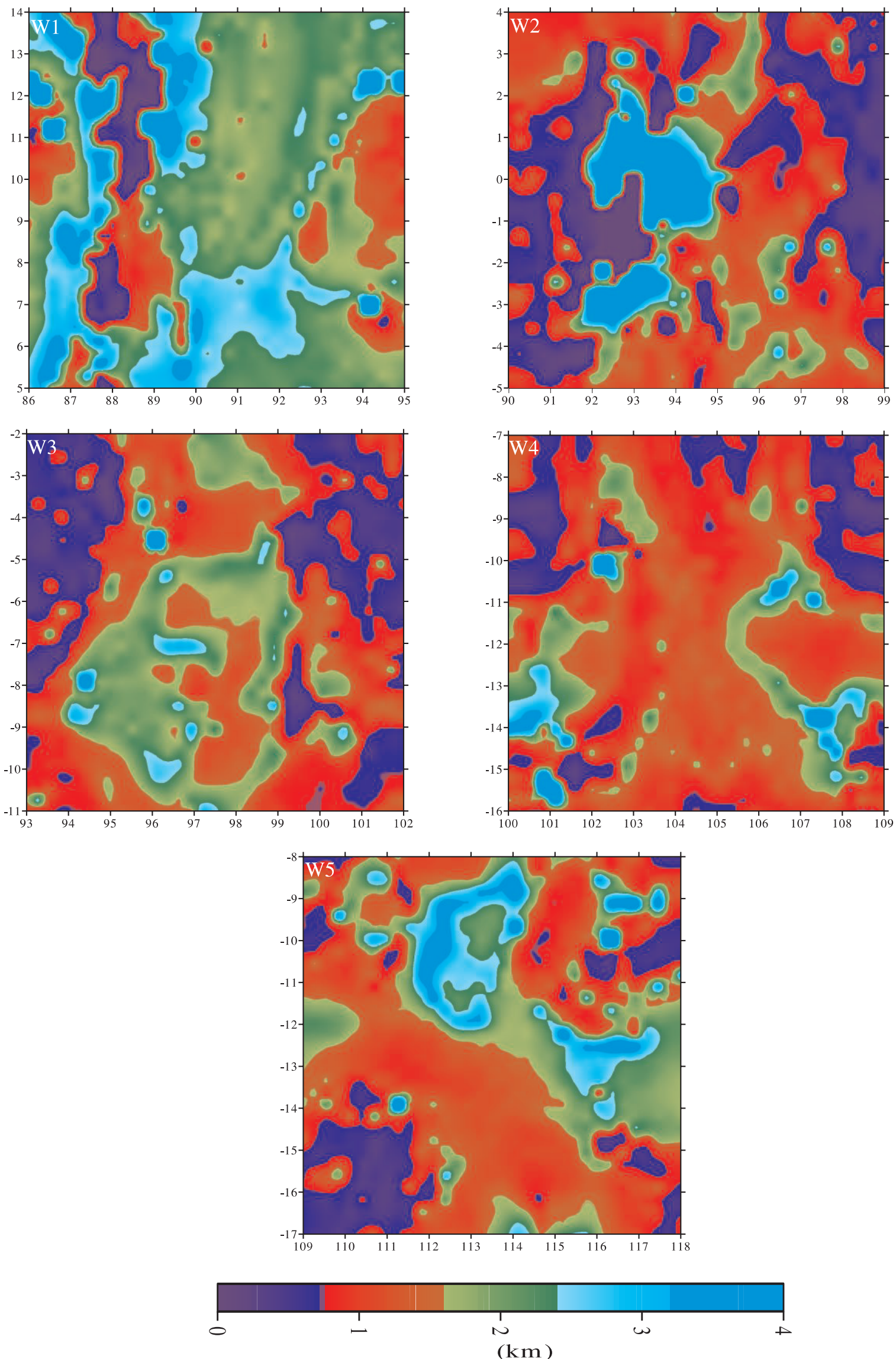

Figure 3. Error on $T_{e}$ estimation corresponding to the windows W1, W2, W3, W4 and W5. 

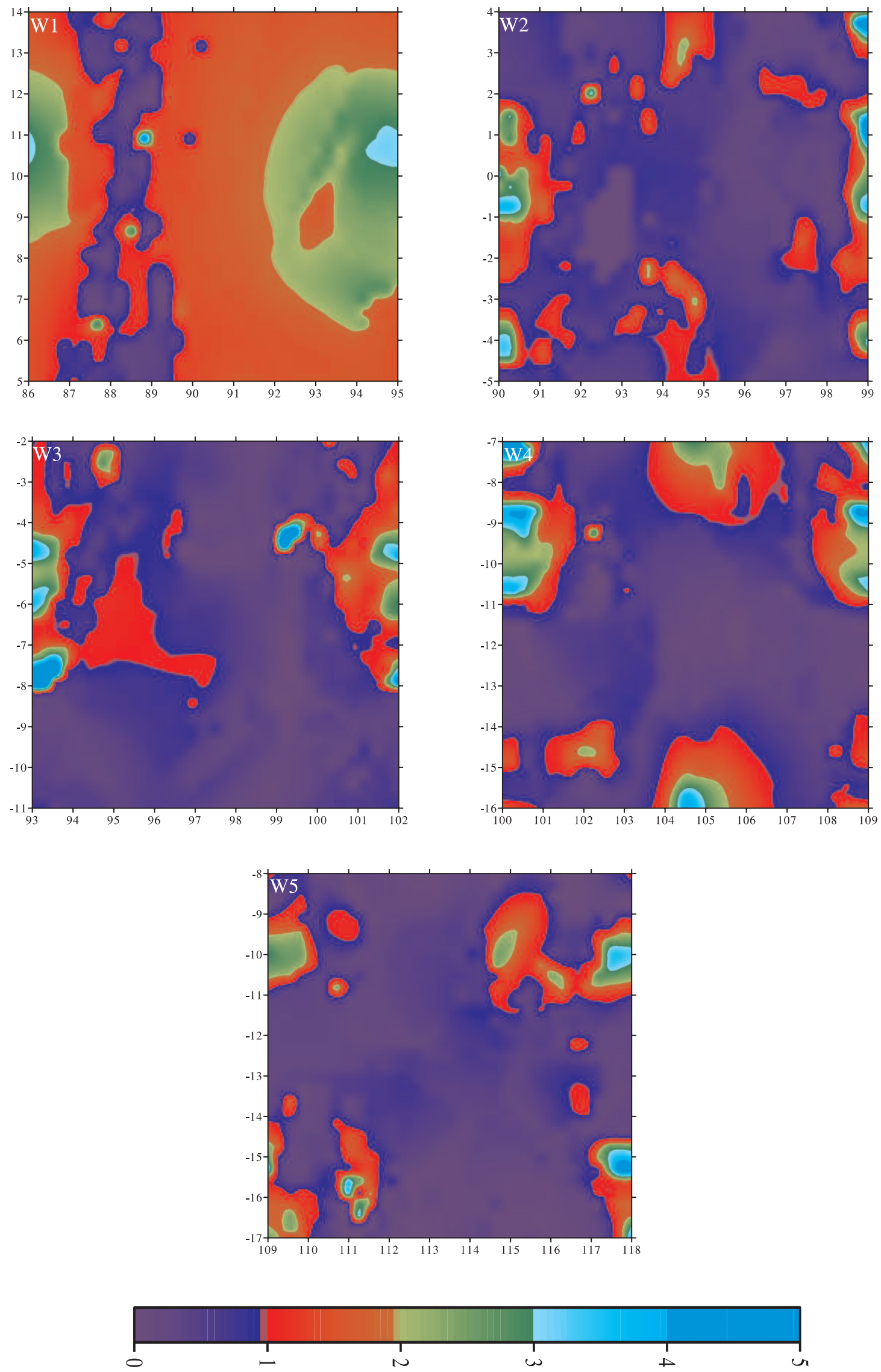

Figure 4. Loading ratio obtained for the Windows W1, W2, W3, W4 and W5. 
high wavenumber thereby producing smoother $T_{e}$ results.

We obtained strong correlation of loading ratio (figure 4) which varies from 0-5 for all the windows of $T_{e}$ estimation which encourages the usefulness of this method. The loading ratio indicates the ratio of subsurface to surface loading as a function of wave number at a particular point around the transitional wavelength. The present methodology allows us to fit the observed admittance function between the gravity and topography data to estimated values predicted from a thin plate flexure model subjected to surface and subsurface loading. Alternatively the fan wavelet technique (Swain and Kirby 2006) employed in the current study, loading equations are applied to the averaged wavelet transforms (Morlet) instead of the Fourier transform of the gravity and topography to compute the surface and subsurface loads. In our study we observed an anti-correlation between the $T_{e}$ and the flexural loading ratio in most of the regions. This type of anti-correlation has been explained by Tassara et al (2007), as the loading ratio is an average of the wavenumber increasing ratio around the transitional wavelength. However, a correlation between high $T_{e}$ and loading ratio $>1$ can also be observed in some small patches within the windows, implying the possibility of anomalous subsurface density variations.

\section{Discussions}

The estimated $T_{e}$ values over Andaman-Sumatra and Java subduction zones in the five windows (figure 2) indeed demonstrate the tectonic regime of both the subducting and over-riding plates near the trench axis. The Andaman-Northern Sumatra subduction zone shown in W1 (figure 2) is part of the Burma micro plate. Kamesh Raju et al (2007) provided a detailed analysis in the Andaman-Sumatra region based on fault plane solutions multi-beam bathymetry, single channel seismic and density modeling. Their observations reveal the active strike-slip motion along the WAF with the presence of back-arc spreading and increased oblique convergence resulting in less frequent earthquakes. $T_{e}$ observations in the Andaman-Northern Sumatra region (Figure 2 W1) shows a high $T_{e}$ range $(40-65 \mathrm{~km})$ which is consistent with the idea of Singh et al (2005) that WAF forms a lithospheric boundary with different friction coefficients promoting discontinuity in coupling or locking strength between subducting Indian plate and Burma plate. They deduced this locking depth as $30-40 \mathrm{~km}$ near the WAF. The historical and neotectonic earthquakes that have occurred in this region include the events of 1914
(M7.2), 1941 (M7.7), 1955 (M7.2), 2004 (M7.2), 2005 (M7.3), 2009 (M7.6) and others, indicating that great magnitudes $(M>8)$ are rare in this region. We interpret that the locking resulted in less deformation and therefore less frequent earthquakes and a strong lithosphere. The rate of subduction in Andaman region is $14 \mathrm{~mm} / \mathrm{yr}$ (Lay et al 2005 ), that in Sumatra is $52-60 \mathrm{~mm} / \mathrm{yr}$, and in Java it is $80 \mathrm{~mm} / \mathrm{Yr}$ (Lasitha et al 2006). It is obvious that as we move from Andaman to Java, the rate of subduction increases and obliquity of convergence with the Indo-Australian plate decreases as Andaman experiences highly oblique subduction and Java experiences normal subduction. In addition, the global positioning system measurements (McCaffrey et al 2000) reveals structural partition between the Sumatra and Java subduction zones of the Indo-Australia plate with trench normal compression within the fore-arc and trench parallel strain along the Sumatran Fault.

A bimodal $T_{e}$ distribution, obvious from the forearc segment of Sumatra $(0-20 \mathrm{~km})$ and Java (20$40 \mathrm{~km}$ ) will be the most diagnostic observations from the $T_{e}$ windows (W2 to W5). A detailed study of spatial elastic thickness variation in the fore-arc region of Andean margin (Pérez-Gussinyé et al 2008) using Bouguer coherence method obtained variable $T_{e}$ from $5-40 \mathrm{~km}$ between western Cordillera and the coastline. They interpreted the high $T_{e}$ to reflect the combined strength of upper continental and oceanic lithospheres along with its cooling processes. Many other authors (Feng et al 2007; Hamza et al 2005; Tassara et al 2007; Polet et al 2000, Anderson et al 2007) express the view that shear velocity, surface heat flow anomaly, temperature structure and seismic anisotropy may influence the geometry of the sinking slab leading to its tectonic segmentation along the margin. Recently Tassara et al (2007) used improved fan wavelet discovery of isostatic function in the Andean margin and obtained $T_{e}$ values $\sim 20 \pm 10 \mathrm{~km}$ in the fore-arc region. Their studies (Tassara et al 2007) indicate that variation in $T_{e}$ near the trenches correlates well with the seismogenic segmentation and earthquake predictability of subduction zones. They infer that the integrated long term strength of coupled slab fore-arc system controls the $T_{e}$. However, Billen and Gurnis (2005), using admittance technique obtained a decrease in the effective elastic thickness by at least $15 \mathrm{~km}$ as approaching the Kermadec trench within the Pacific Ocean plate. The prominent low $T_{e}$ observed over the NER (W1 and W2) and Investigator Ridge (W3) on the subducting plate can be attributed to the isostatic compensation mechanism by which the ridge topographic load is balanced by the deep Moho root into the mantle whereas, low $T_{e}$ obtained over the 

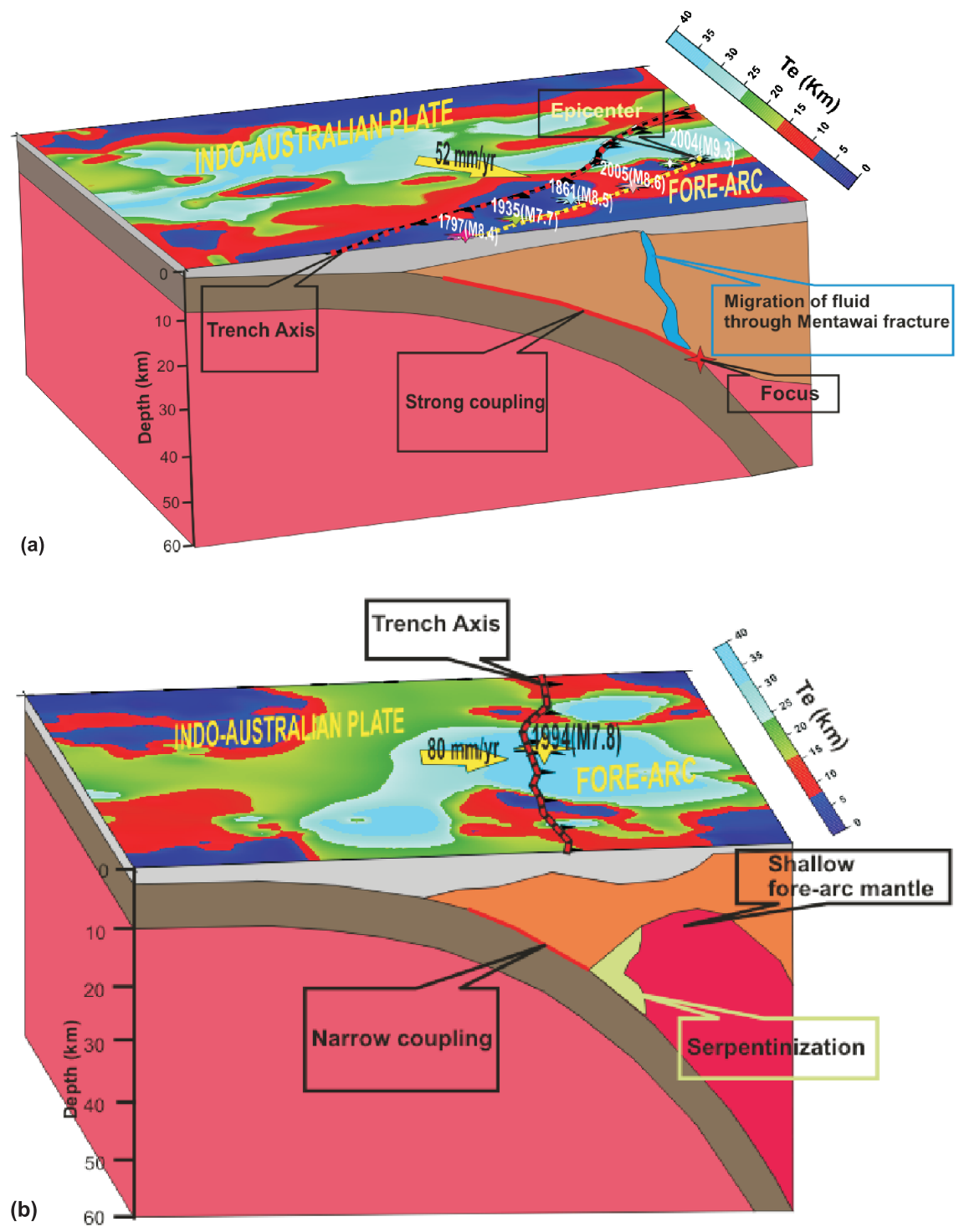

Figure 5. 3-D cartoons for Sumatra-Java subduction zones, demonstrating $T_{e}$ variation along with the subduction geometry and earthquake mechanism (after Grevemeyer and Tiwari 2006). (a) $T_{e}$ surface is exhibiting an oblique convergence of the Indo-Australian oceanic plate at a rate of $52 \mathrm{~mm} / \mathrm{yr}$ along the Sumatra trench and the $L F T_{e}$ patch $\left(T_{e}<20 \mathrm{~km}\right)$. The representation of a strong coupling zone at the interface between the subducting and over-riding crustal segments beneath the $L F T_{e}$ patch is revealing the tectonic correlation between the interseismic coupling and the fore-arc $T_{e}$ variation. The trace of the Mentawai fracture at depth is symbolized by a fractured conduit which is the way of fluid migration from the down-dip region. The earthquake focus is shown at the down-dip, where the subducting crust meets the fore-arc mantle, demonstrating the mechanism of earthquake events plotted at the $T_{e}$ surface. (b) The $T_{e}$ surface representing the Java subduction zone exhibits a normal subduction of the Indo-Australian plate. The spatial $T_{e}$ high at the fore-arc region is explained by means of a shallow fore-arc mantle model (Grevemeyer and Tiwari 2006) and a narrow coupling zone at the interface. Absence of deep lying fractured conduits and hence, the existence of serpentinization at the down-dip explains the comparatively less seismic behaviour of the Java zone.

subducting plate in W3 and W4 can be justified by the local compensation of intermittently scattered bathymetric loads. Our observed $T_{e}$ variation between NER and Sumatra trench zone is overall exhibiting a moderately high range and therefore conforms to Subrahmaniam et al (2008) that NER and its buoyant root have not reached the region of over-riding plate, hence the complexities due to the ridge subduction may not have initialized in the
Sumatra-Java trench zone. Moreover the derived NER values are supporting the earlier $T_{e}$ values computed by Tiwari et al (2003).

Although the relationship between seismicity and spatial variations in $T_{e}$ are far from ideal, the first order correlation is indeed evident as discussed in earlier sections. Shallow focus earthquakes $(\sim 30 \mathrm{~km})$ are mostly observed in SumatraJava fore-arcs (Grevemeyer and Tiwari 2006; 
Konca et al 2008). Grevemeyer and Tiwari (2006) demonstrated evidence that magnitude of the shallow earthquake is regulated by the coupling at the interface between subducting and over-riding plates. They proposed that a serpentinized mantle wedge would limit the width of the coupling zone of Java only to $30-40 \mathrm{~km}$ and that of Sumatra to less than $120 \mathrm{~km}$. Our bimodal $T_{e}$ variation of 0-20 km in Sumatra and 20-40 km in Java substantiate these findings. We infer that $L F T_{e}$ patches are associated with large magnitude seismicity and are the zones of high strain accumulation, resulting from a deficit in slip rate along the crustal interface from the actual rate plate convergence. Konca et al (2008) analyzed the 2004 and 2007 earthquake events, and inferred that these events ruptured only a fraction of ruptured area in 1833, and consists of distinct aspirites (areas of high moment release during large magnitude earthquakes) within a patch of megathrust events. Chlieh et al (2008) used geodetic and paleogeodetic measurements of interseismic strain and imaged heterogenous pattern of coupling in Sumatra region. These patch works of high strain accumulation (Konca et al 2008; Chlieh et al 2008) conform well to the $L F T_{e}$ patches that estimated from isostatic response analysis. Song and Simons (2003) predicted that shear stress is higher where a negative TPGA is observed and lower where a positive TPGA is observed. Hyndman and Peacock (2003) and Moore and Saffer (2001) demonstrated that updip limit is associated with a change of frictional properties in the thrust occurring at temperature of $100-150^{\circ} \mathrm{C}$. Hyndman and Peacock (2003) and Bostock et al (2002) explain the role of water trapped in the crust and mantle and formation of serpentinization. However, numerical modeling and experimental data obtained by Nadege and Bruno (2009) conforming with the models of Grevemeyer and Tiwari (2006) show that serpentine rheology in subduction zones have a strong influence on the mechanical coupling between slab and mantle wedge. Seno (2005) proposed that hydration of fore-arc mantle wedge occurs through the hydrofracturing of subducted crust and inferred that stress state of the wedge would determine the extent of serpentinization of the fore-arc mantle wedge. Our observation of most of the earthquakes aligned along the Mentawai fracture zone within the $L F T_{e}$ patch suggests an upward migration of expelled aquous fluids from the down-thrusting crust through this fractured conduit instead of forming serpentinization at the down-dip region. This will result in a wide interseismic coupling due to the increasing friction at the interface between the subducting and over-riding crustal segments and is assumed to be the possible reason for the strength reduction and the occurrence of shallow-high magnitude seismicity in the Sumatra fore-arc (figure 5a). We now propose that a narrowweak interseismic coupling for Java leads to its comparatively high strength and less seismicity of the fore-arc zone. The normal subduction of an old-cold lithosphere (138 Myr) (Grevemeyer and Tiwari 2006) at a convergence rate of $80 \mathrm{~mm} / \mathrm{yr}$ (Lasitha et al 2006] may promote a decoupling at the interface. Since Java fore-arc is devoid of active fractures of regional extent (Newcomb and McCann 1987), it prevents the migration of water from the interface. Thus, the water released from the subducting crust can percolate into the fore-arc mantle peridotite to form hydrous minerals like serpentine and help for a slippage, thus leading to an earthquake of small magnitude; rather than a large strain accumulation at the interface (figure 5b).

\section{Conclusion}

A summary of our results of flexural analysis applied to the Sumatra-Java subduction zone shows that:

- The fore-arc region has high rigidity $\left(T_{e}\right.$ ranges from $40-65 \mathrm{~km})$ in the Andaman-Northern Sumatra region showed in W1 (figure 2). Although this region is experiencing oblique convergence with the subducting Indo-Australian plate, the locking depth of $30-40 \mathrm{~km}$ near the WAF (Singh et al 2005; Kamesh Raju et al 2007) which lies in close proximity with the forearc segment leads to less deformation and hence greater strength.

- Over the Sumatra fore-arc segment, $T_{e}$ map obtained shows an anomalously Low Fore-arc $T_{e}\left(L F T_{e}\right)$ range $(0-20 \mathrm{~km})$ over the Sumatra fore-arc (figure $2 \mathrm{~W} 2$ and W3) coinciding with the epicenter locations of previous major earthquakes: 2004 (M9.3), 2002 (M7.3), 2005 (M8.6), 1861 (M8.5), 1935 (M7.7), 1797 (M8.4), 1833 (M9.2), 2007 (M8.4 and M7.9) and others. This is suggestive of a very weak lithosphere exhibiting crustal thickening due to diffused deformation (figure 6) at all crustal levels and can thus promote fracturing and upward migration of fluids.

- Over the Java fore-arc segment, a high range of $T_{e}(20-40 \mathrm{~km})$ is obtained as shown in W4 and W5 (figure 2). This is in stark contrast to Sumatra which is suggestive of a strong lithosphere and shallow fore-arc mantle.

- A portion of NER included in W1 and W2 (figure 2) exhibits a low $T_{e}$ value $(\sim 0-15 \mathrm{~km})$, while the adjacent regions on both the flanks of the ridge are showing a progressive increasing pattern of $T_{e}$ range away from the ridge 


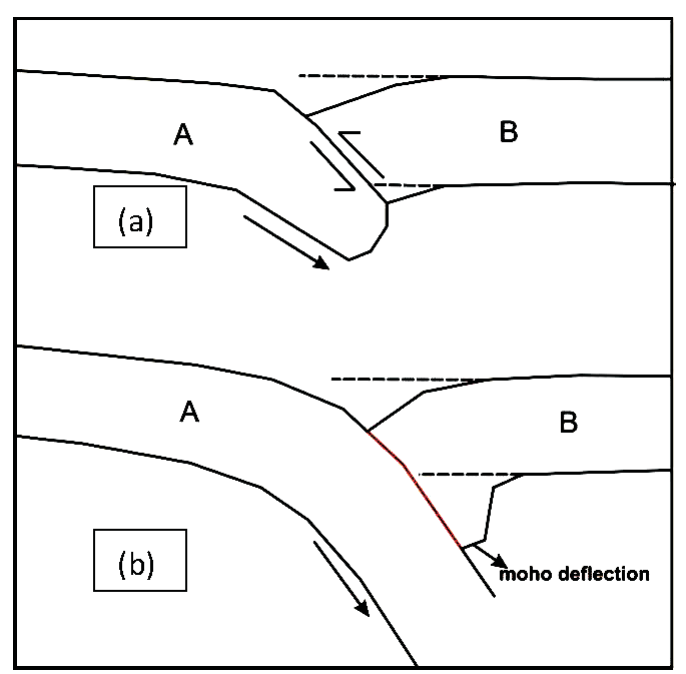

Figure 6. Cartoon demonstrates fore-arc crustal deformation mechanism (a) Couple force is induced at the interface between the under-thrusting (A) and over-riding (B) crusts and the bending and stretching of the over-riding plate begins. (b) After the deformation by stretching of the over-riding crust, the Moho boundary shifts into a deeper position resulting in a wide interface (red line) and subsequent crustal thickening.

axis. A prominent $T_{e}$ low $(\sim 15 \mathrm{~km})$ can also be observed over the Investigator Ridge included in W3 (figure 2). This can be attributed to the isostatic compensation mechanism by which the ridge topographic load is balanced by the deep Moho root into the mantle.

- Low $T_{e}$ over the Indo-Australian plate in $\mathrm{W} 4$ and W5 can be justified by the local compensation of intermittently scattered bathymetric loads.

Along strike variations in $T_{e}$ along the AndamanSumatra-Java fore-arc zone correlate with the geotectonic segmentation of the north eastern Indian Ocean subduction zone and with the pattern of crustal seismicity. Considering yield strength envelopes, a $T_{e}$ value less than $15 \mathrm{~km}$ in the Sumatra region implies the existence of a competent upper crust whose seismogenic thickness is $30 \mathrm{~km}$. Our present method mapped the rigidity structure along the continent-ocean transition over the Indian Ocean active subduction zone, where no previous studies exist of this kind. When we compare the rigidity structure with that of distribution of earthquakes in the Indonesian margin, we observe distinct seismogenic segmentation along the subduction faults with Sumatra and Java showing bimodal $T_{e}$ values. These are first order estimates, which vividly show the causal relationship of rigidity structure and earthquake distribution. However, further studies need to be carried out to improve the understanding of predictability of earthquakes and tsunamis along the Indonesian margin.

\section{Acknowledgements}

This research was supported by INCOIS (Tsu/ 08-09) and DST fast track project. We thank two anonymous reviewers for constructive reviews and several important suggestions that improved the manuscript substantially.

\section{References}

Andersen O B, Knudsen P, Berry P, Freeman J, Pavlis N and Kenyon S 2008 The DNSC07 ocean wide altimetry derived gravity field; Presented EGU, session G1, General Assembly, Vienna, Austria, April 14-18.

Anderson M L, Alvarado P, Beck S and Zandt G 2007 Geometry and brittle deformation of the subducting Nazca plate, central Chile and Argentina; Geophys. J. Int. 171(1) 419-434, doi: 10.1111/j.1365-246X.2007.03483.x.

Andres Tassara 2005 Interaction between the Nazca and South American plates and formation of the AltiplanoPuna plateau: Review of a flexural analysis along the Andean margin $\left(15^{\circ}-34^{\circ} \mathrm{S}\right)$; Tectonophys. 399 39-57.

Audet P and Mareschal J C 2004 Variation in elastic thickness in the Canadian Shield; Earth Planet. Sci. Lett. 226 $17-31$.

Banks R J, Francis S and Hipkin R 2001 Effects of loads in the upper crust on estimates of the elastic thickness of the lithosphere; Geophys. J. Int. 145 291-299.

Banks R J, Parker R L and Huestis S P 1977 Isostatic compensation on a continental scale: Local versus regional mechanism; Geophysic. J. R. Astron. Soc. 51 431-452.

Bassin C, Laske G and Masters G 2000 The current limits of resolution for surface wave tomography in North America; EOS Trans AGU $81 \mathrm{~F} 897$.

Billen M I and Gurnis M 2005 Constraints on subducting plate strength within the Kermadec Trench; J. Geophys. Res. 110 B05407, doi: 10.1029/2004JB003308.

Billen M I, Gurnis M and Simons M 2003 Multiscale dynamics of the Tonga-Kermadec subduction zone; Geophys. J. Int. 153 359-388.

Bostock M G, Hyndman R D, Rondenay S and Pecock S M 2002 An inverted continental Moho and the serpentinization of the forearc mantle; Nature 417 536-538.

Burov E B and Diament M 1995 The effective elastic thickness $\left(T_{e}\right)$ of continental lithosphere: What does it really mean?; J. Geophys. Res. 100 3905-3927.

Chlieh M, Avouac J P, Sieh K, Natawidjaja D H and John Galetzka 2008 Heterogeneous coupling of the Sumatran megathrust constrained by geodetic and paleogeodetic measurements; J. Geophys. Res. 113 B05305, doi: 10.1029/2007JB004981.

Curray J R 2005 Tectonics and history of the Andaman Sea region; J. Asian Earth Sci. 25 187-232.

Curray J R, Moore D G, Lawver L A, Emmel F J, Raitt R W, Henry M and Kieckhefer R 1979 Tectonics of the Andaman Sea and Burma; Am. Assoc. Pet. Geol. Mem. 29 189-198.

Daly E, Brown C, Stark C and Ebinger C 2004 Wavelet and multitaper coherence methods for assessing the elastic thickness of the Irish Atlantic margin; Geophys. J. Int. $159445-459$.

Feng M, Van der Lee S and Assumpcao M 2007 Upper mantle structure of South America from joint inversion of waveforms and fundamental mode group velocities of Rayleigh waves; J. Geophys. Res. 112 B04312, doi: 10.1029/2006JB004449. 
Gopala Rao D, Krishna K S and Sar D 1997 Crustal evolution and sedimentation history of the Bay of Bengal since the Cretaceous; J. Geophys. Res. 102 17,747-17,768.

Grevemeyer I and Tiwari V M 2006 Overriding plate controls spatial distribution of megathrust earthquakes in the Sunda-Andaman subduction zone; Earth Planet. Sci. Lett. 251 199-208.

Hamza V, Silva Dias F J S, Gomes A J L, and Delgadilho Terceros Z G 2005 Numerical and functional representations of regional heat flow in South America; Phys. Earth Planet. Inter. 152 223-256.

Hyndman R D and Peacock S M 2003 Serpentinization of the forearc mantle; Earth Planet. Sci. Lett. 212 417-432.

Irsyam M, Dangkua D T, Hendriyawan, Hoedajanto D, Hutapea B M, Kertapati E K, Boen T and Petersen M D 2008 Proposed seismic hazard maps of Sumatra and Java islands and microzonation study of Jakarta city, Indonesia; J. Earth Syst. Sci. 117(S2) 865-878.

Kamesh Raju K A, Murty G P S, Dileep Amarnath and Mohan Kumar M L 2007 The west Andaman fault and its influence on the aftershock pattern of the recent megathrust earthquakes in the Andaman-Sumatra region; Geophys. Res. Lett. $34 \mathrm{~L} 03305$.

Kirby J F and Swain C J 2004 Global and local isostatic coherence from the wavelet transform; Geophys. Res. Lett. 31 124,608, doi: 10.1029/2004gl021569.

Kirby J F and Swain C J 2006 Mapping the mechanical anisotropy of the lithosphere using a $2 \mathrm{D}$ wavelet coherence and its application to Australia; Phys. Earth. Planet. Interiors 158 122-138, doi: 10.1016/j.pepi. 2006. 03.022, http://dx.doi.org/10.1016/j.pepi.2006.03.022.

Kirby J F and C J Swain 2007 An accuracy assessment of the fan wavelet coherence method for elastic thickness estimation; Geochemistry, Geophysics, Geosystems 9 Q03022, doi: 10.1029/2007GC001773.

Konca A O et al 2008 Partial rupture of a locked patch of the Sumatra megathrust during the 2007 earthquake sequence; Nature 456 631-635.

Krishna K S, Gopala Rao D, Subba Raju L V, Chaubey A K, Shcherbakov V S, Pilipenko A I and Radhakrishna Murthy I V 1999 Paleocene on-spreadingaxis hotspot volcanism along the Ninetyeast Ridge: An interaction between the Kerguelen hotspot and the Wharton spreading center; Earth Planet. Sci. 108(4) 255-267.

Krishna K S, Neprochnov Y P, Gopala Rao D and Grinko B N 2001 Crustal structure and tectonics of the Ninetyeast Ridge from seismic and gravity studies; Tectonics 20(3) 416-433.

Krishna K S, Rao D G, Ramana M V, Subrahmanyam V, Sarma K V L N S, Pilipenko A I, Shcherbakov V S and Murthy I V R 1995 Tectonic model for the evolution of oceanic crust in the northeastern Indian Ocean from the Late Cretaceous to the Early Tertiary; J. Geophys. Res. 100(B10) 20,011-20,024.

Lasitha S, Radhakrishna M and Sanu T D 2006 Seismically active deformation in the Sumatra-Java trencharc region: Geodynamic implications; Curr. Sci. 90(5) 690-696.

Lay T, Kanamori H, Ammon C J, Nettles M, Ward S N, Aster R C, Beck S L, Bilek S L, Brudzinski M R, Butler R, De Shon H R, Ekstrom G, Satake K and Sipkin S 2005 The great Sumatra-Andaman Earthquake of 26 December 2004; Science 308 1127-1133.

Llenos A L and McGuire J J 2007 Inflence of fore-arc structure on the extent of great subduction zone earthquakes; J. Geophys. Res. 112 B09301, doi: 10.1029/ 2007JB004944.
Luis J F and Neves M C 2006 The isostatic compensation of the Azores Plateau: A 3D admittance and coherence analysis; J. Volcanol. Geotherm. Res. 156 10-22.

Malod J A, Karta K, Beslier M O and Zen M T 1995 From normal to oblique subduction: Tectonic relationships between Java and Sumatra; J. Southeast Asian Earth Sci. 12 85-93.

McCaffrey R, Zwick P C, Bock Y, Prawirodirdjo L, Genrich J G, Stevens C W, Puntodewo S S O and Subarya C 2000 Strain partitioning during oblique plate convergence in northern Sumatra: Geodetic and seismologic constraints and numerical modeling; J. Geophys. Res. 105(B12) $28,363-38,376$.

Moore C and Saffer D 2001 Updip limit of the seismogenic zone beneath the accretionary prism of southwest Japan: An effect of diagenetic to low-grade metamorphic processes and increasing effective stress; Geology 29 $183-186$

Nadege H and Bruno R 2009 Stability and dynamics of serpentinite layer in subduction zone; Tectonophys. 465 $24-29$.

National Earthquake information centre, USGS, http:// earthquake.usgs.gov/regional/neic.

National Oceanic and Atmospheric Administration 2003 General Bathymetric Chart of Oceans, http://www.ngdc. noaa.gov/mgg/gebco/grid/development.pdf.

Newcomb K R and McCann W R 1987 Seismic history and seismotectonics of the Sunda Arc; J. Geophys. Res. 92(B1) 421-439.

Parker R L 1972 The rapid calculation of potential anomalies; Geophys. J. R. Astron. Soc. 31 447-455.

Pérez-Gussinyé M, Lowry A R, Phipps Morgan J and Tassara A 2008 Effective elastic thickness variations along the Andean margin and their relationship to subduction geometry; Geochem. Geophys. Geosyst. 9(2) Q02003, doi: 10.1029/2007GC001786.

Polet J, Silver P G, Beck S, Wallace T, Zandt G, Ruppert S, Kind R and Rudloff A 2000 Shear wave anisotropy beneath the Andes from the BANJO, SEDA, and PISCO experiments; J. Geophys. Res. 105(B3) 6287-6304.

Samuel M A, Harbury N A, Bakri A, Banner F T and Hartono L 1997 A new stratigraphy for the islands of the Sumatran Forearc, Indonesia; J. Asian Earth Sci. 15(4-5) 339-380.

Schluter H U, Gaedicke C, Roeser H A, Schreckenberger B, Meyer H, Reichert C, Djajadihardja Y and Prexl A 2002 Tectonic features of the southern Sumatra-western Java fore-arc of Indonesia. Tectonics 21(5) 1047, doi:10.1029/ 2001TC901048.

Scotese C R, Gahagan L M and Larson R L 1988 Plate tectonic reconstruction of the Cretaceous and Cenozoic ocean basins; Tectonophys. 155 27-48.

Seno T 2005 Variation of the downdip limit of the seismogenic zone near the Japanese Islands: Implications for the serpentinization mechanism of the forearc mantle wedge; Earth Planet. Sci. Lett. 231 249-262.

Simoes M, Avouac J P, Cattin R and Henry P 2004 The Sumatra subduction zone: A case for a locked fault zone extending into the mantle; J. Geophys. Res. 109 B10402.

Singh S C et al 2005 Sumatra earthquake research indicates why rupture propagated northward; EOS Trans. AGU 86(48) 497.

Song T A and Simons M 2003 Large trench parallel gravity variations predict seismogenic behavior in subduction zones; Science 301 630-633.

Subrahmanyam C, Gireesh R, Shyam Chand, Kamesh Raju K A and Gopala Rao D 2008 Geophysical characteristics of the Ninetyeast Ridge-Andaman Island 
arc/trench convergent zone; Earth Planet. Sci. Lett. 266(1-2) 29-45.

Swain C J and Kirby J F 2006 An effective elastic thickness map of Australia from wavelet transforms of gravity and topography using Forsyth's method; Geophys. Res. Lett. 23 L02314.

Tassara A, Swain C, Hackney R and Kirby J 2007 Elastic thickness structure of South America estimated using wavelets and satellite-derived gravity data; Earth Planet. Sci. Lett. 253 17-36.
Tiwari V M, Diament M and Singh S C 2003 Analysis of satellite gravity and bathymetry data over Ninety-East Ridge: Variation in the compensation mechanism and implication for emplacement process; J. Geophys. Res. 108 2109, 10.1029/2000JB000047.

Watts A B 2001 Isostasy and Flexure of the Lithosphere, Cambridge Univ. Press, Cambridge, UK.

Watts A B and Burov E B 2003 Lithospheric strength and its relationship to the elastic and seismogenic layer thickness; Earth Planet. Sci. Lett. 213 113-131.

MS received 20 March 2010; revised 4 June 2010; accepted 28 June 2010 